\title{
Synthesis of boron nitride nanotubes employing mechanothermal process and its characterization
}

\author{
S. K. Singhal $\cdot$ A. K. Srivastava $\cdot$ R. P. Pant $\cdot$ \\ S. K. Halder $\cdot$ B. P. Singh $\cdot$ Anil K. Gupta
}

Received: 13 July 2007/ Accepted: 30 May 2008/Published online: 17 June 2008

(C) Springer Science+Business Media, LLC 2008

\begin{abstract}
Multi-walled boron nitride (BN) nanotubes having cylindrical structure were synthesized employing the mechanothermal process. In this process hexagonal boron nitride powder (hBN) was first ball milled for $50-100 \mathrm{~h}$ using a high-energy ball mill and the ball-milled samples were annealed in $\mathrm{N}_{2}$ atmosphere for about $10 \mathrm{~h}$ in the temperature range of $950-1300{ }^{\circ} \mathrm{C}$. The $\mathrm{BN}$ nanotubes exhibited a well-crystallized hexagonal structure with about $25-40 \mathrm{~nm}$ in diameter and up to $1 \mu \mathrm{m}$ length. These BN nanotubes were well characterized using various techniques, such as, XRD, SEM, TEM and Raman Spectroscopy.
\end{abstract}

\section{Introduction}

Nanoscale materials are those materials that have grain structures modulated on a length scale less than $100 \mathrm{~nm}$. As a class, they are called nanostructured materials and are synthesized by means of a wide variety of physical, chemical and mechanical methods. It has been found that the properties of these nanophase materials are different and often superior to those of conventional materials that have phase or grain structures on a coarser size scale. Moreover it is possible to engineer these properties by controlling and varying the sizes of the constituent domains and the manner in which they are assembled. Much research on boron nitride nanotubes has followed by the discovery of carbon nanotubes, based on the structural

S. K. Singhal $(\bowtie) \cdot$ A. K. Srivastava · R. P. Pant ·

S. K. Halder · B. P. Singh - A. K. Gupta

National Physical Laboratory, Dr. K.S.Krishnan Road,

New Delhi 110012, India

e-mail: sksinghal@mail.nplindia.ernet.in similarity between graphite and hexagonal boron nitride $(\mathrm{hBN})$ [1]. A carbon nanotube is a metallic or semiconductor, depending on morphology, i.e. diameter or the number of walls of the tube, whereas a BN nanotube is thought to be insulating and independent of morphology, and thus could find different applications.

The properties of BN materials would be better than other nanomaterial from the view point of structural stability, heating resistance in air, wide and uniform band gap $(\sim 5.5 \mathrm{eV})$ [1]. Because of these superior properties, BN nanotubes are emerging as promising candidate for blue and violet luminescence device materials. Because of the insulating property these $\mathrm{BN}$ nanotubes will find possible applications as a nanoinsulating shield for any conducting material. These nanotubes would also find applications as gas storage materials, single electron transistors, insulators, lubricants and magnetic refrigeration. BN nanotubes possess exceptionally high Young's modulus ( $>1 \mathrm{TPa}$ ) [2]. The high Young's modulus suggests that these nanotubes have exceptional stiffness and therefore, can be used in the synthesis of highly resistant composite materials. This fact combined with their insulating character makes them suitable for applications in which electrically insulating high-strength materials are needed.

There are number of techniques which are currently being used for the synthesis of BN nanotubes and some of them are arc-discharge, chemical vapour deposition (CVD), chemical reaction, laser ablation, arc melting, thermal annealing, etc. All these processes have their own merit and demerits. The first BN nanotubes were prepared by Chopra et al. [3] in 1995 by a carbon free plasma discharge between a BN-packed tungsten rod and a cooled copper electrode, and since then a number of other methods were reported for BN nanotubes. Saito and Maida [4] prepared $\mathrm{BN}$ nanotubes by passing arc discharge between 
$\mathrm{ZrB}_{2}$ electrodes in a nitrogen atmosphere. $\mathrm{BN}$ nanotubes have also been prepared by carbothermal reduction of amorphous boron oxide and boron carbide in the presence of nitrogen between 1100 and $1450{ }^{\circ} \mathrm{C}$ [5]. Some other methods employ chemical methods involving suitable catalysts. Thus, Tang et al. [6] have reported the tubular form of $\mathrm{BN}$ by heating a mixture of boron and iron oxide in the presence of ammonia atmosphere at $1300{ }^{\circ} \mathrm{C}$ for few hours. In another chemical reaction reported by Deepak et al. [7] $\mathrm{BN}$ nanotubes were synthesized by heating a mixture of boric acid with activated carbon, multi-walled carbon nanotubes using catalytic iron particles in the presence of ammonia. Laser ablation method has also turned to be an effective means for the synthesis of BN nanotubes $[8,9]$ and their morphology depends strongly upon the used catalyst. Golberg et al [10] have synthesized multi-walled $\mathrm{BN}$ nanotube ropes by carrying out the reaction of a mixture of boron oxide and multi-walled carbon nanotubes at $1500{ }^{\circ} \mathrm{C}$ in a nitrogen atmosphere in the presence of $\mathrm{MoO}_{3}$ catalyst.

It has been observed that the formation yield and the quantity of $\mathrm{BN}$ nanotubes in all these processes are very low. Further the laser ablation and arc discharge methods require temperatures of the order of $3000{ }^{\circ} \mathrm{C}$ for $\mathrm{BN}$ nanotubes formation. Therefore, there was need to investigate some alternate methods by which these nanotubes could be grown with high yield at relatively lower temperatures. Chen et al [11-13] and Fengqui et al [14] have reported the growth of $\mathrm{BN}$ nanotubes by ball milling of elemental boron (B) in ammonia atmosphere and $\mathrm{BN}$ powder in $\mathrm{Ar}$ or $\mathrm{N}_{2}$ atmosphere followed by isothermal annealing the ball-milled samples at about $1100-1300{ }^{\circ} \mathrm{C}$ in $\mathrm{N}_{2}$ atmosphere for few hours (h). In the work reported by Gerald et al [13] elemental hexagonal B powder was first ball milled for up to $168 \mathrm{~h}$ in a sealed tungsten carbide (WC) container filled with $\mathrm{NH}_{3}$ gas at $300 \mathrm{kPa}$ at ambient temperature. The milled samples were annealed at $1200{ }^{\circ} \mathrm{C}$ in the presence of $\mathrm{N}_{2}$ flow in a tubular furnace for $4-16 \mathrm{~h}$ to observe the growth of $\mathrm{BN}$ nanotubes. This process seems to be very promising for the growth of $\mathrm{BN}$ nanotubes on a large scale and is popularly known as mechanothermal process.

In this paper, a systematic study of the growth of $\mathrm{BN}$ nanotubes using a mechanothermal process in which hBN powder was first ball milled using a high-energy ball mill followed by annealing the as-milled samples for about $10 \mathrm{~h}$ in nitrogen atmosphere at temperatures varied from $950-1300{ }^{\circ} \mathrm{C}$ is reported. It may be noted that while in the earlier work $[13,14]$ the ball milling was performed in the presence of $\mathrm{NH}_{3}$ gas filled in the vessel at a pressure of about $200-300 \mathrm{kPa}$, in the present case the milling was performed at atmospheric pressure and at room temperature.

\section{Experimental details}

\section{Procedure}

In the present work, an almost identical procedure as used by Gerald et al [13] was used for the growth of BN nanotubes except that we used (i) hBN powder instead of elemental B powder, (ii) liquid $\mathrm{NH}_{3}$ solution instead of $\mathrm{NH}_{3}$ gas as the milling media and (iii) ball milling was performed at atmospheric pressure instead of $200-300 \mathrm{kPa}$ at room temperature. However, in both the cases ball milling was carried out in containers fabricated from WC containing grinding balls made of WC. Thus, a WC bowl was loaded with a small quantity of $99 \%$ purity $\mathrm{hBN}$ powder $(\sim 5 \mathrm{gm})$ together with WC balls (powder to ball weight ratio of 1:30). Ball milling was performed in the presence of small amount of acetone and liquid $\mathrm{NH}_{3}$ at a speed of about $300 \mathrm{rpm}$ employing a planetary ball mill. The milling time was varied from 10 to $100 \mathrm{~h}$. BN powder produced during these experiments resulted in highly disordered or amorphous nanostructures. BN nanotubes were grown from these disordered nanostructured powder by isothermal annealing at temperatures varied from 950 $1300{ }^{\circ} \mathrm{C}$ in $\mathrm{N}_{2}$ atmosphere for about $10 \mathrm{~h}$.

\section{Material characterization}

$\mathrm{BN}$ nanotubes in the powder form was dispersed on carbon coated copper grid of approx. $3 \mathrm{~mm}$ diameter having 200 mesh pore size, by making a suspension in acetone. Microstructural characterization at high magnification and reciprocal space analysis were carried out using a transmission electron microscope (TEM, model JEOL JEM 200CX), operated at the electron accelerating voltage of $200 \mathrm{kV}$. A scanning electron microscope (SEM, model LEO 440) equipped with an energy depressive spectrometer (EDS, model Oxford Link ISIS 300) was used to study the topological features and the composition of $\mathrm{B}$ and $\mathrm{N}$ at different regions of the powder material was characterized. Further crystallographic interpretations on the formation of different phases during synthesis of $\mathrm{BN}$ nanotubes were performed by X-ray diffraction (XRD) patterns recorded using a D8 Advanced Bruker Diffractometer.

\section{Results and discussion}

\section{Characterization of starting materials}

The samples were characterized by powder X-ray diffractometer using $\mathrm{CuK}_{\alpha}$ radiation. A graphite monochromator was used to record the background. Figure 1a shows an $\mathrm{X}$-ray diffraction pattern of the starting hexagonal boron 


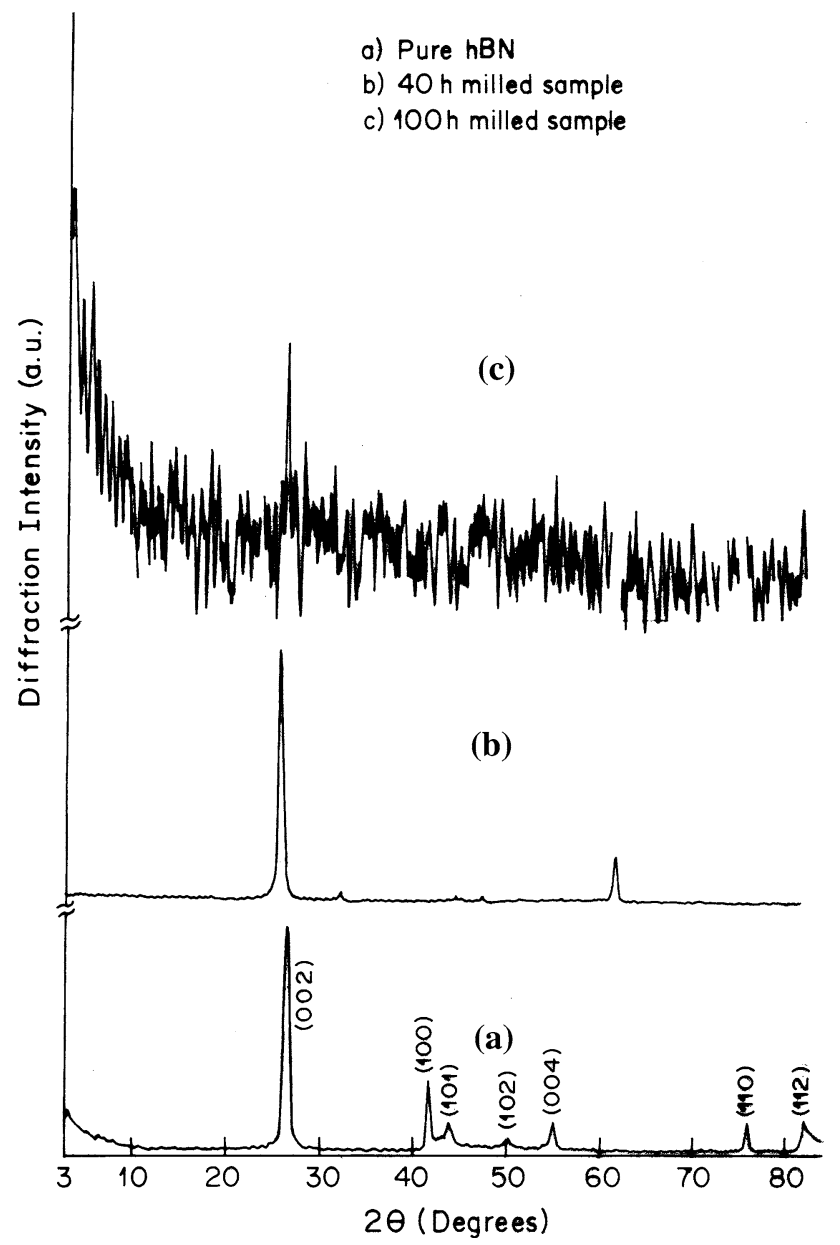

Fig. 1 X-ray diffraction pattern of (a) pure hBN powder (b) after $40 \mathrm{~h}$ of ball milling and (c) after $100 \mathrm{~h}$ of ball milling

nitride powder used in the present work. It was found to be highly crystalline with all peaks of $\mathrm{hBN}$. Figure $1 \mathrm{~b}$ and $\mathrm{c}$ shows the XRD patterns of $40 \mathrm{~h}$ and $100 \mathrm{~h}$ ball-milled BN powder, respectively. It is clear from the SEM micrograph of pure hBN powder (Fig. 2) that the crystal morphology was of needle shape and the size of the crystallites varied from 1 to $3 \mu \mathrm{m}$.

The as-milled samples

To study the effect of ball milling time on the hBN crystallization, the samples were characterized by XRD after ball milling for 4, 10, 40, 75 and $100 \mathrm{~h}$. It was revealed that milling of $40 \mathrm{~h}$ sample did not produce any significant changes in the degree of crystallization. However, the sample produced with $100 \mathrm{~h}$ of ball milling showed a considerable change in the degree of crystallization of BN. The XRD patterns of the pure hBN powder and those produced after 40 and $100 \mathrm{~h}$ of ball milling are shown in Fig. 1. From this figure it is clear that the BN powder produced after $100 \mathrm{~h}$ of milling was highly disordered

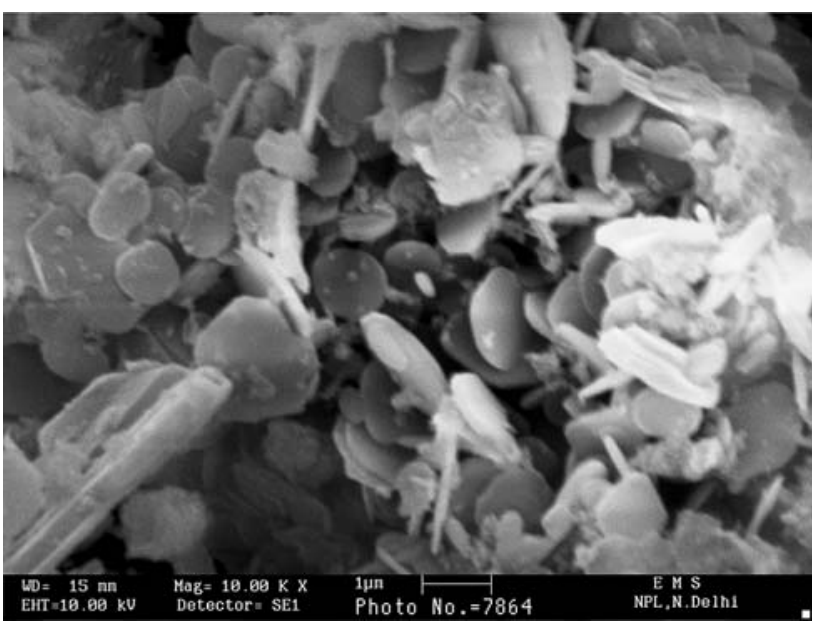

Fig. 2 SEM micrograph of pure hBN

(almost amorphous) structure. The morphology of BN crystallites remained unchanged (needle type) in the BN samples produced below $100 \mathrm{~h}$ of ball milling; however, the size of the crystallites reduced to nanoscale between 75 and $100 \mathrm{~h}$ of ball milling as observed by SEM characterization. The crystallite size reduced to $150-200 \mathrm{~nm}$ at $75 \mathrm{~h}$ of ball milling and $70-100 \mathrm{~nm}$ at $100 \mathrm{~h}$ of ball milling. Figure 3 shows a SEM micrograph of $\mathrm{BN}$ powder ball milled at $100 \mathrm{~h}$ and this powder was subsequently used for the growth of BN nanotubes.

The annealed samples

$\mathrm{BN}$ nanotubes were grown from $\mathrm{BN}$ powder ball milled for $100 \mathrm{~h}$ by subsequently annealing at temperature 950-1300 ${ }^{\circ} \mathrm{C}$ in the presence of $\mathrm{N}_{2}$ atmosphere for duration

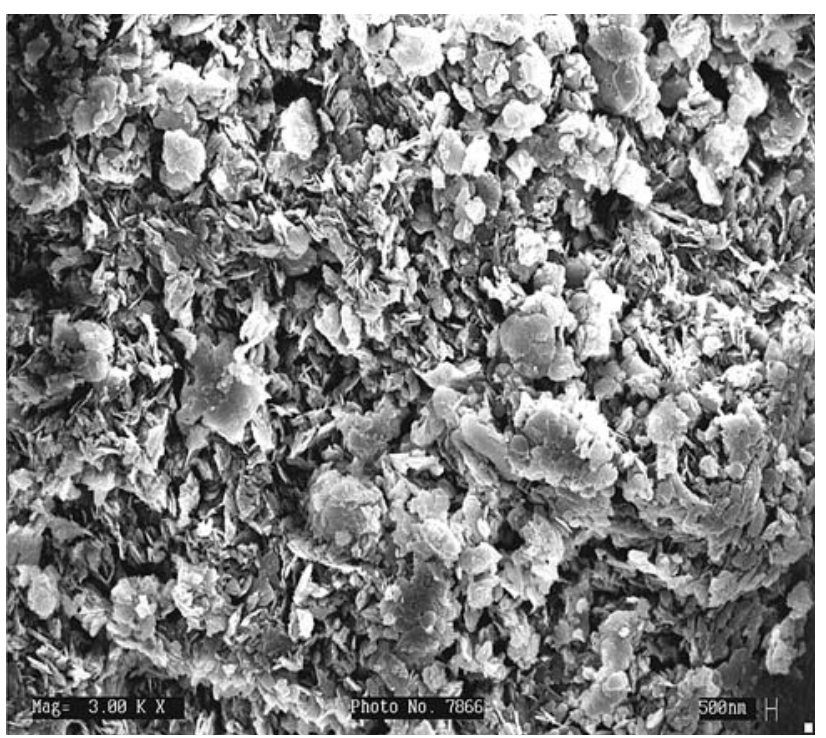

Fig. 3 SEM micrograph of hBN powder produced with $100 \mathrm{~h}$ of ball milling 
Fig. 4 XRD of BN nanotubes produced with $100 \mathrm{~h}$ of ball milling followed by isothermal annealing in $\mathrm{N}_{2}$ atmosphere at (a) $950{ }^{\circ} \mathrm{C}$ (b) $1200{ }^{\circ} \mathrm{C}$ and (c) $1300{ }^{\circ} \mathrm{C}$ [d values are in $\mathrm{A}^{\circ}$ ]

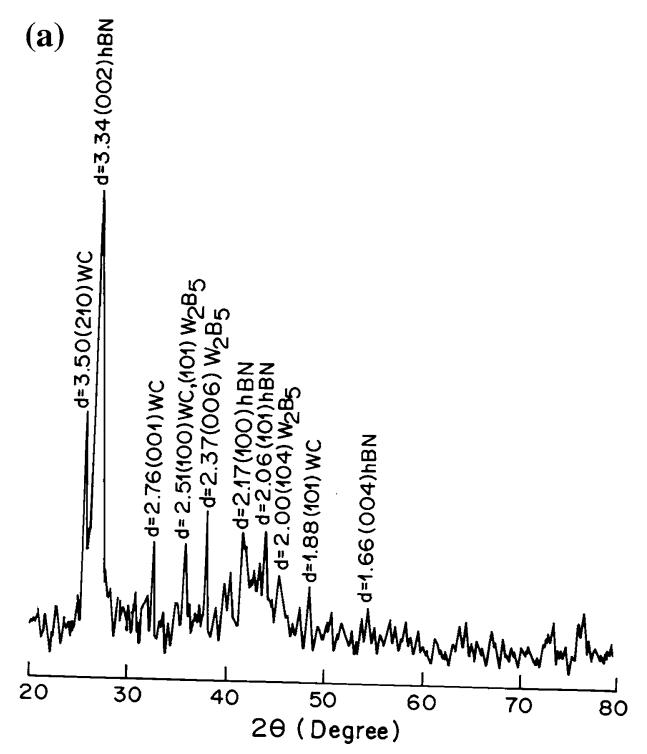

(b)

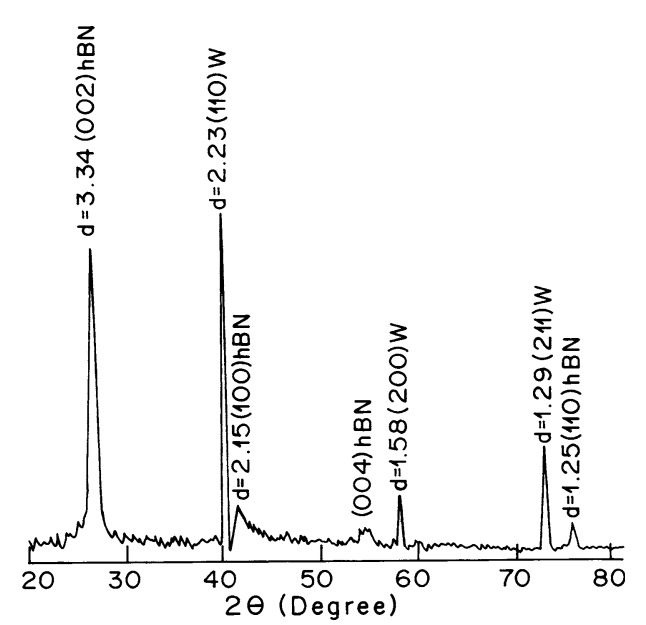

of $10 \mathrm{~h}$. XRD, Raman and TEM techniques were used to characterize these nanotubes. The results of the abovecharacterized nanotubes are discussed in the subsequent sections.

Figure $4 \mathrm{a}-\mathrm{c}$ shows X-ray diffraction patterns of $\mathrm{BN}$ nanotubes grown from $100 \mathrm{~h}$ ball-milled $\mathrm{BN}$ samples and annealed at three different temperatures namely 950, 1200 and $1300{ }^{\circ} \mathrm{C}$ in $\mathrm{N}_{2}$. Ball-milled samples annealed at a lower temperature of $950{ }^{\circ} \mathrm{C}$ showed some growth of $\mathrm{BN}$ nanotubes as observed in Fig. 4a. This X-ray pattern also shows the peaks of WC along with $\mathrm{hBN}$ peaks. This contamination could be because of the abrasion of WC from the surface of WC bowl and WC balls during the milling operation. It could also be seen that small quantity of $\mathrm{W}_{2} \mathrm{~B}_{5}$ was also observed in this sample. It is clear from Fig. $4 \mathrm{~b}$ and $\mathrm{c}$ where the samples were annealed at 1200 and $1300{ }^{\circ} \mathrm{C}$ that a relatively high yield of $\mathrm{BN}$ nanotubes (as compared to the samples annealed at $950{ }^{\circ} \mathrm{C}$ ) was produced as evidenced from the peak intensity of (002) plane of hBN. It was also observed that there are well-defined peaks of $\mathrm{W}$ metal in these two cases, which indicates that WC has been transformed into $\mathrm{W}$ metal.

The high-energy (during ball milling) impacts severe deformation on the particles and create fresh, new surfaces as well as a high density of dislocations and other structural defects. Such a high defect density can accelerate the diffusion process. The nanocrystalline BN produced at the end of milling serves as seed for nanotube growth during subsequent annealing process. During this process the nitridation reaction further proceeds and complete with the formation of $\mathrm{BN}$ nanotubes in the presence of $\mathrm{N}_{2}$ gas. It has been found that ball milling of $\mathrm{hBN}$ or $\mathrm{B}$ powder was normally carried out in the presence of an inert atmosphere, e.g. $\mathrm{NH}_{3}, \mathrm{~N}_{2}$, Ar, etc to avoid the oxidation. In the present work liquid ammonia was used as the milling medium instead of ammonia gas as used by Chen et al [13]. Ball milling using either of two media (liquid $\mathrm{NH}_{3}$ or $\mathrm{NH}_{3}$ gas) leads to the formation of a precursor (nanosized disordered 
BN phases or disordered B powder mixed with WC nanoparticles) from which $\mathrm{BN}$ nanotubes were grown during subsequent annealing. In the present work an almost complete amorphization of BN was observed after $100 \mathrm{~h}$ of ball milling of hBN in liquid ammonia solution as shown in Fig. 1c. However, Gerald and Chen [13] used elemental hexagonal B powder (h-B) as the starting material and ball milling was carried out in the presence of $\mathrm{NH}_{3}$ gas. In this case a much longer milling time of about $168 \mathrm{~h}$ is required to produce nanosized disordered $\mathrm{B}$ powder and the milled sample was not completely amorphized as observed in the present work. We speculate that this precursor is formed more easily if $\mathrm{hBN}$ powder was used as the starting material instead of h-B powder, as during the milling of $\mathrm{B}$ powder only some $\mathrm{NH}_{3}$ gas reacts to form nanosized disordered BN phases. It is likely that a relatively lower mechanical energy is required to damage the $\mathrm{hBN}$ powder to produce nanosized aBN powder as compared to that required in case of elemental h-B powder which in turn is related to the milling time as well. Thus, while in the Chen's work a milling time of $168 \mathrm{~h}$ is required to produce nanosized disordered B powder mixed with WC nanoparticles [13], a much lower milling time of about $100 \mathrm{~h}$ is required in the present work, and an almost complete amorphization of $\mathrm{BN}$ was observed. This is the main advantage of the present investigation.

Annealing of the ball-milled samples is usually done in a nitrogen-containing atmosphere such as $\mathrm{N}_{2}, \mathrm{~N}_{2}-\mathrm{H}_{2}$ or $\mathrm{NH}_{3}$ gases. However, $\mathrm{NH}_{3}$ atmosphere is preferred for the annealing of milled $\mathrm{B}$ powder. During the annealing process, $\mathrm{NH}_{3}$ decomposes into $\mathrm{N}$ and $\mathrm{H}_{2}$ gases (which are more reactive than $\mathrm{N}_{2}$ gas) at temperatures above $458 \mathrm{~K}$ [13], and the released $\mathrm{N}$ gas reacts with milled $\mathrm{B}$ powder to form $\mathrm{BN}$ nanotubes. The nitriding reaction rate of $\mathrm{B}$ with $\mathrm{N}$ is relatively less at $1000{ }^{\circ} \mathrm{C}$ and with the increase in annealing time and temperature the $\mathrm{BN}$ nanotube growth also increases because of increased nitridation degree and reaction rate. Recent studies have shown that annealing in $\mathrm{NH}_{3}$ gas produced thin multi-walled cylindrical BN nanotubes with a diameter less than $10 \mathrm{~nm}$ [15]. However, as already mentioned milling can also be done either in $\mathrm{N}_{2}$ or in $\mathrm{Ar}$ atmosphere especially when $\mathrm{hBN}$ powder was used as the starting material to avoid the oxidation. It has been observed that nanosized WC particles abraded during the milling operation also get mixed with nanosized amorphous BN powder. These nanoparticles are converted into $\mathrm{W}$ metal during the annealing process. The nanosized $\mathrm{W}$ metal particles are found to serve as heterogenous nucleation sites and promote $\mathrm{BN}$ nanotube formation through its catalytic action. These particles might be in the liquid or quasi-liquid state during BN nanotube growth. The role of $\mathrm{W}$ as a catalyst in the $\mathrm{BN}$ nanotube formation has been reported by Bengu and Marks [16] and Chopra et al. [3].
Annealing of the ball-milled BN powder can be done either in $\mathrm{NH}_{3}$ or $\mathrm{N}_{2}$ atmosphere as the $\mathrm{BN}$ nanotube formation takes place by solid state nucleation and growth mechanism through a thermally activated process of surface diffusion [17]. It may be noted that in the present investigation the annealing of milled samples was carried out in the presence of $\mathrm{N}_{2}$ gas. The XRD analysis reveals the BN structure and the presence of $\mathrm{W}$ catalyst as indicated by $\mathrm{BN}$ (002) and the catalyst peaks. BN nanotubes of diameter of 25-40 $\mathrm{nm}$ are observed when annealing was carried out in $\mathrm{N}_{2}$ gas as shown in the TEM micrographs (Fig. 5). The yield of BN nanotubes was found to increase both with the increase in annealing time as observed by Gerald et al. [13] as well as by increase in annealing temperature as observed in the present study. According to Gerald et al. a small quantity of $\mathrm{BN}$ nanotubes was produced from the annealing of h-B powder milled for $168 \mathrm{~h}$ at $1200{ }^{\circ} \mathrm{C}$. The annealing time was varied from 4 to $16 \mathrm{~h}$. The nanotubes exhibited cylindrical structure at lower annealing time $(4-10 \mathrm{~h})$ and thick walled conical (bamboo-type) at longer annealing time $(16 \mathrm{~h})$. The yield of $\mathrm{BN}$ nanotubes was found to increase with increasing annealing time at a constant

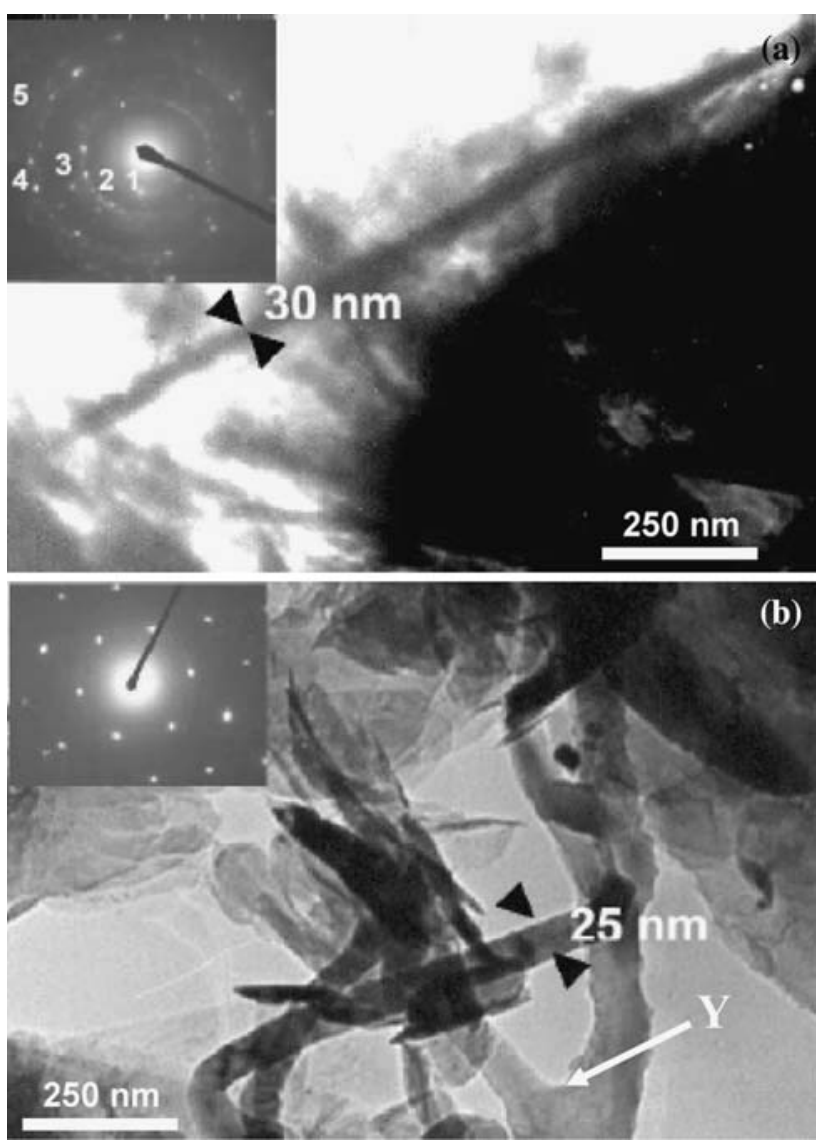

Fig. 5 TEM micrographs of $\mathrm{BN}$ nanotubes produced at $1300{ }^{\circ} \mathrm{C}(\mathbf{a}$ and $\mathbf{b}$ ). Insets show electron diffraction patterns recorded from (a) an aggregates of $\mathrm{BN}$ nanotubes and (b) from a single nanotube 
annealing temperature of $1200{ }^{\circ} \mathrm{C}$. With the increase in annealing time from 4 to $16 \mathrm{~h}$ at $1200{ }^{\circ} \mathrm{C}$ the amount of $\mathrm{W}$ nanoparticles converted from WC nanoparticles increases thereby increasing the number of nucleation sites for the growth of $\mathrm{BN}$ nanotubes [13]. However, no quantitative data on yield has been reported by Chen et al [13]. In the present study we observe an increase in the yield of $\mathrm{BN}$ nanotubes with the increase in annealing temperature from 950 to $1300{ }^{\circ} \mathrm{C}$ presumably because most of the WC nanoparticles abraded from WC container were not converted into $\mathrm{W}$ nanoparticles at lower annealing temperature $\left(950{ }^{\circ} \mathrm{C}\right)$ and the number of nucleation sites necessary for the growth of BN nanotubes were lower as compared to the one produced at higher annealing temperatures. Further, at lower annealing temperature $\left(950^{\circ} \mathrm{C}\right)$ the nucleation and growth of $\mathrm{BN}$ nanotubes has just started and the yield increased from $\sim 30 \%$ to about $50-60 \%$ as the annealing temperature was increased from 950 to $1300{ }^{\circ} \mathrm{C}$ as indicated by the increase in intensity of (002) peak of hBN in the XRD patterns of BN nanotubes and shown in Fig. 4a-c. Thus, the present method can also be used for the synthesis of large quantity of $\mathrm{BN}$ nanotubes. The yield of $\mathrm{BN}$ nanotubes produced using this mechanothermal process is also much higher than that produced using other techniques such as arc-discharge, laser ablation, substitution reaction and chemical reactions. Thus, a maximum yield of about $200 \mathrm{mg}$ of BN nanotubes has been reported by Zhi et al [18] from the chemical reaction of $\mathrm{FeO}, \mathrm{MgO}$ and $\mathrm{B}$ powder at a temperature ranging from 1100 to $1700{ }^{\circ} \mathrm{C}$ in the presence of $\mathrm{NH}_{3}$ gas using an induction furnace.
However, the weight of starting material taken is not mentioned. In the present work $1 \mathrm{~g}$ of the milled $\mathrm{BN}$ powder yielded about $600 \mathrm{mg}$ of $\mathrm{BN}$ nanotubes at $1300{ }^{\circ} \mathrm{C}$.

The BN nanotubes were characterized using transmission electron microscopy (TEM). At high magnifications, transmission electron microscope (JEOL TEM 200CX), operated at $200 \mathrm{kV}$ was used to study the morphologies prevailing within the bulk of BN nanotube samples. Figure $5 \mathrm{a}$ and $\mathrm{b}$ shows the TEM micrographs of BN nanotubes produced in the present work from ball-milled hBN powder annealed at $1300{ }^{\circ} \mathrm{C}$ in nitrogen atmosphere for $10 \mathrm{~h}$. Small quantities of BN nanotubes with a tube diameter of about $25-40 \mathrm{~nm}$ and length up to about $1 \mu \mathrm{m}$ were clearly seen in these micrographs. In most of the samples annealed at $950-1300{ }^{\circ} \mathrm{C}$ for $10 \mathrm{~h}, \mathrm{BN}$ nanotubes exhibited the cylindrical structure as observed in the TEM micrographs. We did not observe the growth of conical BN nanotubes having bamboo-like structure as observed by Chen et al [13]. We also noticed the growth of $\mathrm{BN}$ nanotubes having Y-junction in some samples annealed at $1300{ }^{\circ} \mathrm{C}$ and marked by an arrow in TEM micrograph as shown in Fig. 5. It is important to mention that the structural nanoscaled junctions like $\mathrm{Y}$ and $\mathrm{T}$ are useful in different electronic applications for fabricating connectors, etc. [19]. These BN nanotubes were seen in aggregate and distributed throughout the specimen. Crystallographic interpretation of these nanotubes was also carried out by reciprocal space analysis, employing the selected area electron diffraction (SAED). A SAED recorded from an aggregate of nanotubes is depicted as inset in Fig. 5a. Some of the important planes on Debye rings
Fig. 6 TEM micrographs of $\mathrm{BN}$ nanotubes produced at $950{ }^{\circ} \mathrm{C}\left(\mathbf{a}\right.$ and b) and at $1200{ }^{\circ} \mathrm{C}$ (c and d)
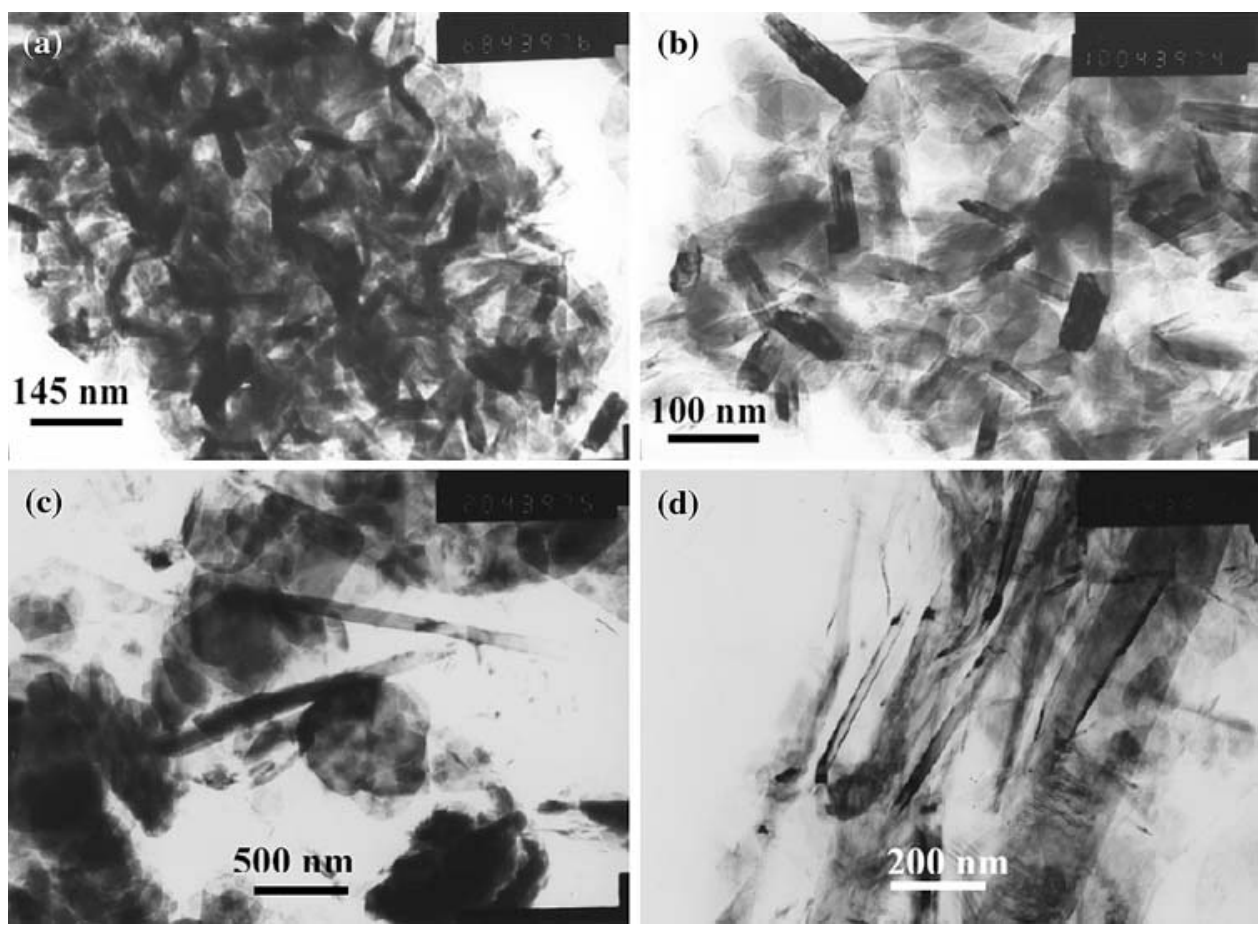

(d)

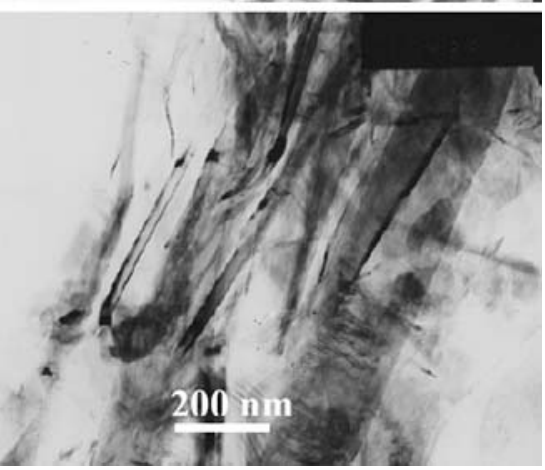


\{numbers $1-5$ as marked on SAED, Fig. 5a $\}$ are indexed as $0002,10 \overline{1} 0,10 \overline{1} 2,11 \overline{2} 0$ and $11 \overline{2} 4$ corresponding to interplanar spacing of $0.33,0.21,0.18,0.13$ and $0.10 \mathrm{~nm}$, respectively. A SAED recorded from a relatively coarser nanotube, along [0001] zone axis of hexagonal BN, has been elucidated as inset in Fig. 5b. The spotty electron diffraction pattern \{inset in Fig. 5b\} further leads an important characteristic of these materials that the $\mathrm{BN}$ nanotubes are single crystalline and are in agreement with XRD analysis (Fig. 4b and c). As an illustrative example, the micrographs recorded on samples at lower annealing temperatures (below $1300{ }^{\circ} \mathrm{C}$ ) i.e. at $950{ }^{\circ} \mathrm{C}$ and $1200{ }^{\circ} \mathrm{C}$ are given in Fig. $6 \mathrm{a}-\mathrm{d}$.
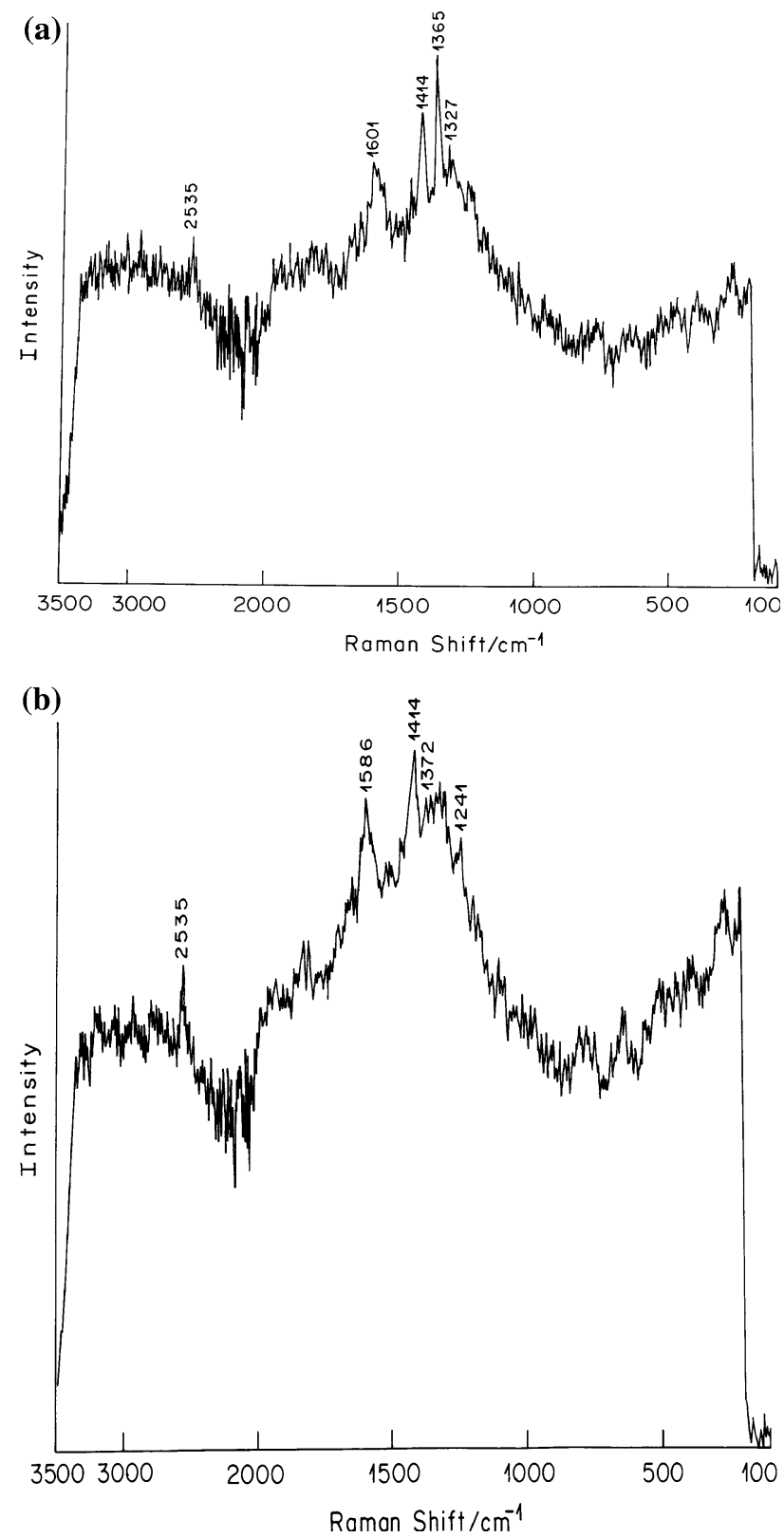

Fig. 7 Raman Spectrum of (a) pure $\mathrm{hBN}$ powder and (b) $\mathrm{BN}$ nanotubes produced at $1300{ }^{\circ} \mathrm{C}$
It is seen that the sample annealed at $950{ }^{\circ} \mathrm{C}$, has just developed BN nanotubes of short dimensions (length: 50$150 \mathrm{~nm}$ and diameter: $\sim 10-30 \mathrm{~nm}$ ) dispersed throughout in the microstructure $\{$ Fig. $6 a$ and b . On increasing the annealing temperature to $1200{ }^{\circ} \mathrm{C}$, the nanotubes have grown significantly (length: $\sim 500 \mathrm{~nm}-1 \mu \mathrm{m}$ and diameter: $\sim 20-40 \mathrm{~nm}$ ) as shown in Fig. 6c and d. It is worth stating that although the tubes are already evolved at the annealing temperature of $950{ }^{\circ} \mathrm{C}$ and further grown at $1200{ }^{\circ} \mathrm{C}$, however, clear and distinct morphologies of $\mathrm{BN}$ nanotubes are evidenced only at annealing temperature of $1300{ }^{\circ} \mathrm{C}$ as shown in Fig. 5.

BN nanotubes were also characterized using laser Raman spectroscopy with Ar ion as a laser source. The laser power was kept below $50 \mathrm{~mW}$ for the Raman measurements to minimize the influence of temperature variation in the measurements. Fig. $7 \mathrm{a}$ and $\mathrm{b}$ shows the Raman spectra of pure $\mathrm{hBN}$ powder and $\mathrm{BN}$ nanotubes produced by mechanothermal process after annealing at $1300{ }^{\circ} \mathrm{C}$. For pure hBN powder a well-defined peak for $\mathrm{E}_{2 \mathrm{~g}}$ mode is observed at $1365 \mathrm{~cm}^{-1}$ as shown in Fig. 7a. However, in case of $\mathrm{BN}$ nanotubes this peak in the Raman spectrum is shifted to higher frequencies by $7 \mathrm{~cm}^{-1}$ and is recorded at $1372 \mathrm{~cm}^{-1}$ as shown in Fig. 7b. The broadening of peak is due to the formation of nanostructured material.

The micro structural feature observed in the present work indicates that the formation of nanotube is due to preferential growth of $\mathrm{BN}$ at lattice scale in a hexagonal crystal structure. A single crystal electron diffraction pattern \{inset in Fig. 5b \} elucidates the preferential growth direction along [0001], which is basically the c-axis of hexagonal unit cell of $\mathrm{BN}$, related to the highest density, thermodynamically most stable plane. Although a detailed high-resolution electron microscopy was not the theme of

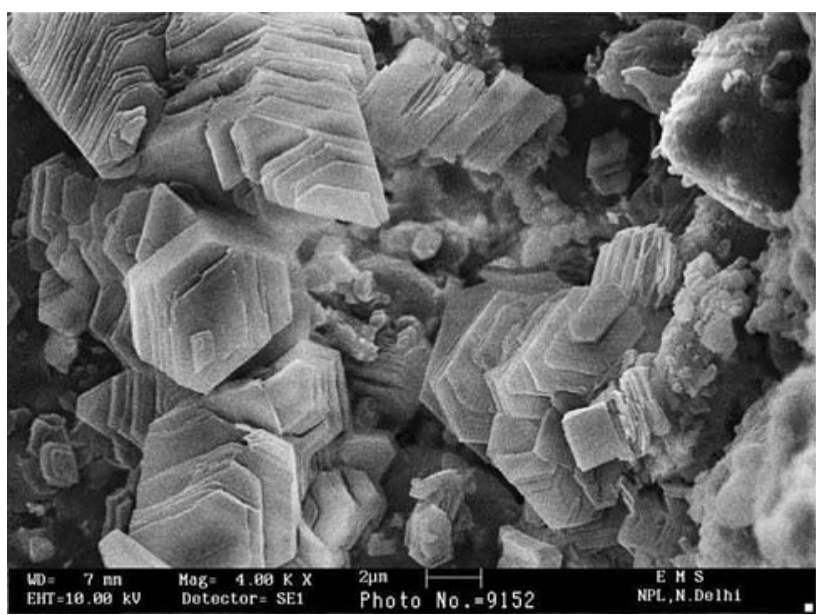

Fig. 8 SEM micrograph of a sample showing the stacking of BN layers during the formation of $\mathrm{BN}$ nanotubes at $950{ }^{\circ} \mathrm{C}$ 
the present investigation, however, the topographical features observed on these samples at micro scale (Fig. 8) further exemplifies that the stacking of $\mathrm{BN}$ during solid state transformation in layers along a certain direction attributes that the growth of $\mathrm{BN}$ even at micro-scale tries to preserve the crystallographic symmetry.

\section{Conclusions}

Multi-walled BN nanotubes were synthesized from $100 \mathrm{~h}$ ball-milled hBN powder, and subsequently annealed in the temperature range $950-1300{ }^{\circ} \mathrm{C}$ in $\mathrm{N}_{2}$ atmosphere for about $10 \mathrm{~h}$. It has been observed that the milling time, annealing time and temperatures are the key factors for the growth of BN nanotubes. In the process of producing BN nanotubes, the hBN powder is first ball milled for $100 \mathrm{~h}$ in liquid ammonia solution to convert it to nanosized amorphous BN powder mixed with WC nanoparticles, which gets converted into BN nanotubes during annealing in nitrogen atmosphere. It has also been observed that nanosized $\mathrm{W}$ metal particles abraded from the walls of WC container promote the growth of $\mathrm{BN}$ nanotube and thus this $\mathrm{W}$ acts as a catalyst during the annealing process. The yield of nanotubes depends on annealing temperature, quantity of amorphous BN nanophase and to some extent the catalyst material. It has been observed that the morphology of these nanotubes was mostly cylindrical as confirmed by TEM studies and the SAED pattern shows hexagonal crystalline structure. The length of $\mathrm{BN}$ nanotube has a profound effect on annealing temperature, as is clear that at higher annealing temperature of $1300{ }^{\circ} \mathrm{C}$ the length of nanotube was found to be longer up to $1 \mu \mathrm{m}$ as compared to lower annealing temperature $\left(950{ }^{\circ} \mathrm{C}\right)$ where the length was found to be about $50-150 \mathrm{~nm}$.

Acknowledgements The authors are grateful to the Director, National Physical laboratory, New Delhi, India, for his permission to publish these results. Thanks are also due to Mr. K.N. Sood and
Dr. Nita Dilawar for their help in SEM and Raman spectroscopy studies, respectively.

\section{References}

1. Crespi VH, Cohen ML, Rubio A (1997) Phys Rev Lett 79:2093. doi:10.1103/PhysRevLett.79.2093

2. Chopra NG, Zettl A (1998) Solid State Commun 105:297. doi: 10.1016/S0038-1098(97)10125-9

3. Chopra NG, Luyken RJ, Cherrey K, Crespi VH, Cohen ML, Louie SG et al (1995) Science 269:966. doi:10.1126/science. 269.5226.966

4. Saito Y, Maida M (1999) J Phys Chem A 103:1291. doi:10.1021/ jp983510c

5. Bartnitskaya TS, Oleinik GS, Pokropivnyi AV, Pokropivnyi VV (1999) JETP Lett 69:163

6. Tang CC, De La Chapelle ML, Li P, Liu YM, Dang HY, Fan SS (2001) Chem Phys Lett 342:492. doi:10.1016/S0009-2614(01) 00635-2

7. Deepak FL, Vinod CP, Mukhopadhayay K, Govindaraj A, Rao CNR (2002) Chem Phys Lett 353:345. doi:10.1016/S0009-2614 (02)00007-6

8. Golberg D, Bando Y, Eremets M, Takemura K, Kurashima K, Yusa H (1996) Appl Phys Lett 69:2045. doi:10.1063/1.116874

9. Laude T, Matsumi Y, Marraud A, Jouffrey B (2000) Appl Phys Lett 76:3239. doi:10.1063/1.126593

10. Golberg D, Bando Y, Kurashima K, Sato T (2000) Chem Phys Lett 323:185. doi:10.1016/S0009-2614(00)00480-2

11. Chen Y, Chadderton LT, Gerald JF, Williams JS (1999) Appl Phys Lett 74:2960. doi:10.1063/1.123979

12. Chen Y, Conway M, Williams JS, Zou J (2002) J Mater Res 17:1896. doi:10.1557/JMR.2002.0281

13. Gerald JDF, Chen Y, Conway ML (2003) Appl Phys A 76:107. doi:10.1007/s00339-002-1441-5

14. Fengqui J, Chaunbao C, Hong X, Ziguang Y (2006) Chin J Chem Engg 14:389. doi:10.1016/S1004-9541(06)60088-8

15. Yu J, Bill C, Li P, Zou J, Chen Y (2007) J Mater Sci 42:4025. doi: 10.1007/s10853-006-0381-4

16. Bengu E, Marks LD (2001) Phys Rev Lett 86:2385. doi: 10.1103/PhysRevLett.86.2385

17. Chen Y, Gerald JDF, Chadderton LD, Chaffron L (1999) Appl Phys Lett 74:2782. doi:10.1063/1.124012

18. Zhi C, Bando Y, Tan C, Golberg D (2005) Solid State Commun 135:67. doi:10.1016/j.ssc.2005.03.062

19. Zhang J, Li Z, Xu J (2005) J Mater Sci Tech 21:128 